\title{
A EDUCAÇÃO SEXUAL E A PROMOÇÃO DA EQUIDADE DE GÊNERO NO ENFRENTAMENTO DA VIOLÊNCIA DOMÉSTICA CONTRA MULHERES
}

\author{
EDUCACIÓN SEXUAL Y PROMOCIÓN DE LA EQUIDAD DE GÉNERO EN LA \\ LUCHA CONTRA LA VIOLENCIA DOMÉSTICA CONTRA LAS MUJERES
}

\author{
SEXUAL EDUCATION AND PROMOTING GENDER EQUITY IN FACE OF \\ DOMESTIC VIOLENCE AGAINST WOMEN
}

\author{
Mariana Passafaro Mársico AZADINHO ${ }^{1}$ \\ Angelita de Lima OLIVEIRA ${ }^{2}$ \\ Débora Raquel da Costa MILANI ${ }^{3}$
}

RESUMO: A violência contra as mulheres constitui-se em uma das principais formas de violação aos direitos humanos. Segundo a Organização Mundial da Saúde, o Brasil se posiciona no $5^{\circ}$ lugar dos países que mais matam mulheres no mundo no contexto doméstico e familiar. Essa violência decorre de uma cultura preconceituosa, discriminatória, patriarcalista, machista e racista. Para combatê-la, é preciso, além de políticas públicas efetivas, a integração do Poder Público com as áreas da educação, por meio de ações educacionais que disseminem os direitos humanos e os valores éticos de irrestrito respeito à dignidade da pessoa humana com a perspectiva de gênero. Nesse sentido, por meio de um levantamento bibliográfico, com análise crítica acerca da temática abordada, este trabalho tem por objetivo ressaltar a importância da educação sexual e da promoção da equidade de gênero no processo educativo de aprendizagem e de socialização, concluindo que essa educação contribui com a formação de um pensamento crítico e com o desenvolvimento social e colabora com a construção de uma cultura igualitária, com a igualdade de gênero e enfrentamento de todas as formas de violência, discriminação e preconceito contra as mulheres.

PALAVRAS-CHAVE: Educação sexual. Equidade de gênero. Violência contra mulheres.

RESUMEN: La violencia contra la mujer es una de las principales formas de violación de los derechos humanos. Según la Organización Mundial de la Salud, Brasil ocupa el quinto lugar entre los países que más matan mujeres en el mundo en el contexto doméstico y familiar. Esta violencia proviene de una cultura prejuiciosa, discriminatoria, patriarcal, sexista y racista. Para combatirlo es necesaria, además de políticas públicas efectivas, la integración del Poder Público con las áreas de educación, a través de acciones educativas que difundan los derechos humanos y los valores éticos del respeto irrestricto a la dignidad

1 Universidade Estadual Paulista (UNESP), Taquaritinga - SP - Brasil. Mestranda no Programa de Pósgraduação em Educação Sexual. ORCID: https://orcid.org/0000-0002-8489-7358. E-mail: mamarsico@gmail.com

${ }^{2}$ Universidade Estadual Paulista (UNESP), Araraquara - SP - Brasil. Mestranda no Programa de Pós-graduação $\begin{array}{lllll}\text { em Educação } & \text { Sexual. } & \text { ORCID: } & \text { https://orcid.org/0000-0001-6696-9752. } & \text { E-mail: }\end{array}$ angelitalimalima28@outlook.com.br

${ }^{3}$ Universidade Estadual Paulista (UNESP), Matão - SP - Brasil. Docente no Programa de Pós-graduação em Educação Sexual. Doutorado em Educação Escolar (UNESP). ORCID: https://orcid.org/0000-0003-4650-8777. E-mail: deb.milani@yahoo.com.br 
de la persona humana con la perspectiva de género. En este sentido, mediante un relevamiento bibliográfico, con un análisis crítico de la temática abordada, este trabajo tiene como objetivo resaltar la importancia de la educación sexual y la promoción de la equidad de género en el proceso educativo de aprendizaje y socialización, concluyendo que esta educación contribuye con la formación del pensamiento crítico y con el desarrollo social y colabora con la construcción de una cultura igualitaria, con igualdad de género y frente a todas las formas de violencia, discriminación y prejuicio contra las mujeres.

PALABRAS CLAVE: Educación sexual. Equidad de género. La violencia contra las mujeres.

ABSTRACT: Violence against women is one of the main forms of violation of human rights. According to the World Health Organization, Brazil ranks 5th in the countries that kill the most women in the world in the domestic and family context. This violence stems from a prejudiced, discriminatory, patriarchal, sexist and racist culture. To combat it, it is necessary, in addition to effective public policies, the integration of the Public Power with the areas of education, through educational actions that disseminate human rights and the ethical values of unrestricted respect for the dignity of the human person with the perspective of gender. In this sense, by means of a bibliographic survey, with a critical analysis of the theme addressed, this work aims to highlight the importance of sex education and the promotion of gender equity in the educational process of learning and socialization, concluding that this education contributes with the formation of critical thinking and with social development and collaborates with the construction of an egalitarian culture, with gender equality and facing all forms of violence, discrimination and prejudice against women.

KEYWORDS: Sex education. Gender equity. Violence against women.

\section{Introdução}

A violência contra mulheres é considerada uma grave violação de direitos humanos e sua legitimação e perpetuação têm sido possíveis em razão dos mitos prescritos na sociedade, que devem ser combatidos. Essa violência permanece como uma das mais cruéis e evidentes manifestações da desigualdade de gênero no Brasil, compondo um cotidiano perverso sustentado por relações sociais profundamente machistas.

De acordo com os dados da organização internacional Human Rights Watch (HRW, 2019), o Brasil enfrenta uma epidemia de violência doméstica, apontando que em 2017, das 4.539 mulheres assassinadas, pelo menos 1.133 foram vítimas de feminicídio - expressão mais extrema da violência contra as mulheres. E os números podem ser ainda maiores ao considerar que muitos casos não são enquadrados corretamente como violência de gênero.

Todos os dias, um número significativo de mulheres, jovens e meninas são submetidas a alguma forma de violência no Brasil. Sob diversas formas e intensidades, a violência de 
gênero é recorrente e se perpetua nos espaços públicos e privados, encontrando nos assassinatos a sua expressão mais grave.

De fato, o próprio conceito definido na Convenção Interamericana para Prevenir, Punir e Erradicar a Violência contra a Mulher, realizada em Belém do Pará em 1994, em seu artigo $1^{\circ}$, aponta para esta amplitude, definindo violência contra as mulheres como "qualquer ação ou conduta, baseada no gênero, que cause morte, dano ou sofrimento físico, sexual ou psicológico à mulher, tanto no âmbito público como no privado" (BRASIL, 2008). Vale dizer que nessa convenção o Brasil também se comprometeu a agir efetivamente para acabar com a violência contra as mulheres.

Importante dizer que essa violência nem sempre é reconhecida por fazer parte do modo de viver da sociedade, escondendo-se no senso comum. Para Chauí (1991), senso comum é um conjunto de crenças, valores, saberes e atitudes que julgamos naturais porque são transmitidos de geração a geração, sem questionamentos, que nos dizem como são e o que valem as coisas e os seres humanos, e como devemos avaliá-los e julgá-los. Segundo a autora, o senso comum cristalizado no modo de pensar e de sentir de uma sociedade forma o sistema de preconceitos.

Esse sistema de preconceitos permeia todas as relações sociais e irá afetá-las de forma profunda e negativa, estabelecendo diferenças entre as pessoas, negando direitos fundamentais e gerando conflitos, o que produz efeitos devastadores: perda do respeito pela pessoa humana; restrição à liberdade; introdução da desigualdade; estabelecimento e manutenção da discriminação; promoção da injustiça (DALLARI, 1996/1997).

Diferentes preconceitos relacionados à classe social, gênero, etnia, faixa etária etc. permeiam a sociedade. Eles apresentam-se em todos os campos da vida social, fazendo parte do modo de viver da sociedade. Assim, estão presentes também no campo da sexualidade, entendida como parte integral da personalidade de todo ser humano e construída por meio da interação entre o indivíduo e as estruturas sociais (WAS, 1999).

De acordo com o senso comum e seu sistema de preconceitos, as diferenças entre homens e mulheres são verdades e fruto da própria natureza - e, portanto, imutáveis. Ademais, além de estabelecerem diferenças, também criam hierarquia, de modo que a mulher ocupa uma posição socialmente inferior. Com relação ao machismo, que se baseia nessa hierarquização, afirma Chauí (1991, p. 227):

[...] arriscaríamos as seguintes hipóteses para compreendê-lo e ao seu avesso complementar: em primeiro lugar, a repetição, no interior da casa, do que se passa na sociedade e na política como um todo, isto é, a privatização e a 
pessoalização das formas de autoridade; em segundo lugar, também a reiteração do mecanismo sócio-político de transformação da assimetria (no caso homem-mulher, pais-filhos, irmão-irmã) em hierarquia, a diferença sendo simbolizada pelo mando e pela obediência; em terceiro lugar, a compensação pela falta de poder real no plano sócio-político, o machismo funcionando como racionalização, assim como a feminilidade ('atrás de todo grande homem, há uma grande mulher', indicando que há um poder ou autoridade femininos que se exercem sob a condição de serem dissimulados e ocultados pela obediência e pelo recato).

Segundo Vaccari (2001), embora se costume falar em violência sexual, pois exercida por pessoas de um sexo contra pessoas do outro, é mais adequado falar de "violência de gênero", pois exercida por uma parcela da população (gênero masculino) sobre outra (gênero feminino). Assim, a mulher está sujeita a determinado tipo de violência "por ser mulher", porque em geral a violência se dá contra o diferente, contra o considerado socialmente inferior.

Portanto, o conceito de gênero (social) é fundamental para que se compreenda e supere os preconceitos e a relação assimétrica entre homens e mulheres, permitindo a análise da desigualdade entre eles a partir do construído e a participação em conjunto da busca de soluções para a superação da desigualdade (VACCARI, 2001).

A violência de gênero está presente na cultura de todos os países, independentemente do seu grau de desenvolvimento. Ela se expressa e se reproduz culturalmente por meio de comportamentos irrefletidos, aprendidos histórica e socialmente, nas instituições com família, escola, igreja, Estado, que contribuem diretamente para a opressão masculina sobre a feminina. "Tais diferenças são reforçadas pelas instituições sociais, sociedade e Estado, servindo como um instrumento de poder das classes dominantes para subjugar as classes subalternizadas.” (TAVARES; NERY, 2012).

Nesse sentido, o presente artigo objetiva ressaltar a importância da educação sexual e da promoção da equidade de gênero no processo educativo de aprendizagem e de socialização, contribuindo com a formação de um pensamento crítico e o desenvolvimento social e colaborando com a construção de uma cultura igualitária, com a igualdade de gênero e, consequentemente, com o enfrentamento de todas as formas de violência, discriminação e preconceito contra as mulheres.

Quanto à metodologia, o presente estudo baseou-se na abordagem qualitativa de pesquisa de cunho bibliográfico com análise crítica sobre a problematização e a reflexão acerca da temática abordada. 


\section{O combate à violência contra as mulheres}

O combate à violência contra a mulher no Brasil vem de longa data. O ditado popular "em briga de marido e mulher não se mete a colher" foi contestado e desmistificado pelo movimento feminista que tomou força nos anos 1970, o qual produziu reflexões e ações, demonstrando que a violência contra a mulher é sustentada e se alimenta pelo sistema capitalista, patriarcal e racista. Neste mesmo período, expuseram a violência como um mecanismo de poder dos homens sobre as mulheres, gerado por uma sociedade desigual, aprofundando e difundindo os estudos em torno das relações sociais de gênero, instrumento de reflexão fundamental para compreendermos a construção social do homem e da mulher na sociedade (COELHO; ZELIC, 2019).

São múltiplas as formas pelas quais a violência se manifesta, sendo considerada como "qualquer ação ou conduta, baseada no gênero, que cause morte, dano ou sofrimento físico, sexual ou psicológico à mulher, tanto no âmbito público como no privado" (BRASIL, 2008).

Tal definição abarca, portanto, diferentes formas de violência, tais como: a violência doméstica ou em qualquer outra relação interpessoal, em que o agressor conviva ou tenha convivido no mesmo domicílio que a mulher; a violência ocorrida na comunidade e que seja perpetrada por qualquer pessoa, compreendendo, entre outros, violação, abuso sexual, tortura, tráfico de mulheres, prostituição forçada, sequestro e assédio sexual; e a violência perpetrada ou tolerada pelo Estado ou seus agentes, onde quer que ocorra (violência institucional) (BRASIL, 2008).

A violência doméstica e familiar, dessa forma, pode ser considerada um tipo específico de violência contra a mulher. Uma característica marcante dessa violência é o fato de ela ser perpetrada principalmente por pessoas que mantêm ou mantiveram com a vítima uma relação de intimidade. Além disso, fatores culturais podem influenciar tanto o nível de violência, quanto a forma como as mulheres lidam com a situação de violência a que estão expostas.

De acordo com o II Plano Nacional de Políticas para as Mulheres (BRASIL, 2008), as desigualdades de gênero são entendidas como desigualdades estruturantes da sociedade brasileira, sob a ideia de que os valores e crenças sobre capacidades e habilidades de homens e mulheres definem espaços e possibilidades disponíveis a cada um destes grupos. A divisão sexual de tarefas e responsabilidades explicita claramente tal concepção, pois estão calcadas em estereótipos e pré-conceitos que definem qual a contribuição dos diferentes grupos para a sociedade. 


\title{
A educação sexual e a mudança social
}

De modo geral, referências ao contexto cultural que marcam determinada sociedade justificam tais desigualdades, entendendo-se que comportamentos preconceituosos e fenômenos como o da violência doméstica contra as mulheres decorrem de uma cultura discriminatória, patriarcalista, machista e racista. Além do mais, a transmissão cultural se dá nos diversos processos de socialização aos quais os indivíduos estão submetidos, especialmente por meio de instituições como a família, a escola, a igreja e o Estado. (BRASIL, 2008).

Segundo Louro (2012, p. 89-90),

\begin{abstract}
se admitirmos que a escola não apenas transmite conhecimentos, nem mesmo apenas os produz, mas que ela também "fabrica" sujeitos, produz identidades étnicas, de gênero, de classe; se reconhecemos que essas identidades estão sendo produzidas através de relações de desigualdade; se admitimos que a escola está intrinsecamente comprometida com a manutenção de uma sociedade dividida e que faz isso cotidianamente, com nossa participação ou omissão [...]; e, por fim, se não nos sentimos conformes com essas divisões sociais, então, certamente, encontramos justificativas não apenas para observar, mas, especialmente, para tentar interferir na continuidade dessas desigualdades.
\end{abstract}

Nesse sentido, para Crociari e Perez (2019), o professor deve levar em consideração a heterogeneidade da sala de aula e que cada criança carrega consigo uma imensa bagagem cultural, fruto de experiências vividas no âmbito familiar e atentar-se para utilizar ferramentas valorosas para discorrer cotidianamente sobre atividades, brincadeiras e conversas livres de preconceitos e desigualdades, contribuindo para a desconstrução da desigualdade de gêneros.

Portanto, a educação, tanto no meio escolar quanto na socialização, auxilia na construção dos comportamentos diferenciados. "Os sujeitos aprendem a portar-se da forma como socialmente serão aceitos e tal aprendizado na maioria das vezes não se dá de forma consciente" (LUCIFORA; REINA; MUZZETI; SILVA, 2019, p. 1404).

Assim, no processo de socialização ou educação, em todas as suas vertentes (informal, formal, não-formal), esse sistema de preconceito, que representa uma forma velada de violência, é repassado para as novas gerações. Por isso a necessidade de se educar para a reflexão e crítica.

Para combater os preconceitos é preciso interferir na escola, visando uma educação efetivamente voltada para a cidadania e para a liberdade. Desta forma, é de interesse da sociedade como um todo que escolas, famílias, estudantes e outros atores sociais trabalhem em conjunto.

RPGE- Revista on line de Política e Gestão Educacional, Araraquara, v. 24, n. esp. 3, p. 1727-1742, dez., 2020. e-ISSN:1519-9029 DOI: https://doi.org/10.22633/rpge.v24iesp3.14280 
A Educação é um dos fatores indispensáveis para o surgimento de mudança social necessária e capaz para que apareça uma sociedade inclusiva e não assimilacionista, com capacidade de encarar a diferença como valor e não como um desvio social de padrões normais (SILVA, 2007).

No Brasil, desde 2004, o Plano Nacional de Políticas para as Mulheres trata a educação como um dos eixos fundamentais para a construção de uma sociedade igualitária entre mulheres e homens. A preocupação com a igualdade de gênero, raça, etnia, liberdade de orientação sexual, com fortalecimento dos direitos humanos, perpassa transversalmente o planejamento das políticas federais, devendo a educação de qualidade estar intrinsecamente associada à busca da igualdade entre os seres humanos e à valorização da diversidade da sociedade brasileira (BRASIL, 2013).

Nesse sentido, o II Plano Nacional de Políticas para as Mulheres (BRASIL, 2008) propôs uma intervenção pública de caráter multissetorial que deve buscar, simultaneamente, desenvolver ações que: desconstruam as desigualdades e combatam as discriminações de gênero; interfiram nos padrões sexistas/machistas ainda presentes na sociedade brasileira; promovam o empoderamento das mulheres; garantam um atendimento qualificado e humanizado àquelas em situação de violência. Logo, a noção de enfrentamento não se restringe apenas à questão do combate, mas compreende também as dimensões da prevenção, da assistência e da garantia de direitos das mulheres.

Importante salientar que no âmbito preventivo, estão ações que desconstruam os mitos e estereótipos de gênero e que modifiquem os padrões sexistas, perpetuadores das desigualdades de poder entre homens e mulheres e da violência contra as mulheres. A prevenção inclui ações educativas, bem como culturais que disseminem atitudes igualitárias e valores éticos que colaborem para a valorização da paz e para o irrestrito respeito às diversidades de gênero, raça/etnia, geração, orientação sexual, entre outras.

A Educação Sexual também pode ser entendida como "toda a ação ensinoaprendizagem sobre a sexualidade humana, seja ao nível de conhecimento de informações básicas, seja ao nível de conhecimento e/ou discussões e reflexões sobre valores, normas, sentimentos, emoções, e atitudes relacionadas à vida sexual" (FIGUEIRÓ, 2010, p. 3).

Uma educação em sexualidade abrangente e igualitária baseia-se no conhecimento e respeito do corpo, na segurança das práticas sexuais, na partilha das responsabilidades, no reconhecimento das pessoas como sujeitos sexuais de pleno direito, na ausência de estereótipos, violência, dominação ou constrangimentos de qualquer espécie (TEIXEIRA; MARQUES, 2012). 
A Educação Sexual tem como um de seus objetivos contribuir para a quebra de jugos sociais opressores.

De acordo com Maia e Ribeiro (2011, p. 79):

A Educação Sexual deveria fornecer informações e organizar um espaço onde se realizariam reflexões e questionamentos sobre a sexualidade. Deveria esclarecer sobre os mecanismos sutis de repressão sexual a que estamos submetidos e sobre a condição histórico-social em que a sexualidade se desenvolve. Deveria também ajudar as pessoas a terem uma visão positiva da sexualidade, a desenvolver uma comunicação mais clara nas relações interpessoais, a elaborar seus próprios valores a partir de um pensamento crítico, a compreender melhor seus comportamentos e o dos outros e a tomar decisões responsáveis a respeito de sua vida sexual.

Maia e Ribeiro (2011, p. 77) optam por adotar educação sexual como "o processo pedagógico que visa uma formação específica e intencional sobre sexualidade, e o que dela decorrente são comportamentos e atitudes, ética e valores, práticas e concepções".

Logo, a ação pedagógica realmente pautada na diversidade cultural deve ter como princípio uma política curricular da identidade e da diferença. Na educação escolar, trabalhar na perspectiva da diversidade cultural significa uma ação pedagógica que vai além do reconhecimento de que os alunos sentados nas cadeiras de uma sala de aula são diferentes, por terem suas características individuais e pertencentes a um grupo social, mas é preciso efetivar uma pedagogia da valorização das diferenças (NOGUEIRA; FELIPE; TERUYA, 2008).

Deve-se refletir sobre o processo educacional como uma prática educativa vinculada com a própria vida. A ampliação do tempo do estudante na escola precisa estar acompanhada de outras extensões, como os espaços e as experiências educacionais que acontecem dentro e fora dos limites físicos da escola, bem como a intervenção de novos atores no processo educativo de crianças, adolescentes e jovens (BRASIL, 2009).

Segundo o Programa Mais Educação, a escola deve compartilhar sua responsabilidade pela educação, sem perder seu papel de protagonista, porque sua ação é necessária e insubstituível, mas não é suficiente para dar conta da tarefa da formação integral. Propostas pedagógicas devem buscar estabelecer laços, vínculos e diálogos entre os saberes escolares e os saberes comunitários e que afirme a educação como um direito de todos (BRASIL, 2009).

Assim, diferentes atores sociais (Poder Público, comunidade escolar e sociedade civil) devem se unir para a construção permanente de um projeto educativo que respeite e promova os direitos humanos e o exercício da democracia, possibilitando ações e intervenção que poderão auxiliar na construção permanente de sujeitos de direitos no âmbito escolar e, desta forma, contribuirão para a formação de sujeitos mais humanos e sensíveis em nossa 
sociedade, em um efetivo combate de diversas violações aos direitos humanos, como a violência doméstica e familiar contra mulheres.

Essa ação em conjunto com educar para a vivência dos direitos humanos a partir do ambiente escolar envolve experiências que permitam às crianças, aos adolescentes e jovens, tanto na escola quanto em outros espaços de convivência, o exercício da ética como o aprendizado do cuidado de si, desenvolvendo experiências que possibilitem aprendizagens com relação à preservação da integridade física, psíquica e emocional, da liberdade, da autonomia, da participação, da proteção, da solidariedade, do respeito à diversidade etc., dando o contorno da dimensão ética que deve estar presente no ideário e vivência dos direitos humanos (BRASIL, 2009).

Quanto mais formos capazes de aprender a cuidar de nós mesmos, mais seremos capazes de cuidar dos outros e de nos tornarmos responsáveis pelos demais em nossa sociedade. Isto é, sermos cidadãos comprometidos com o bem-estar de todos que estão à nossa volta, buscando viver e nos guiar, então, pelo princípio do cuidado de si e pela ética (BRASIL, 2009).

A noção de direitos humanos traz consigo a expressão de aprimoramentos produzidos nas relações sociais, políticas e humanas entre pessoas e em sociedade. O Relatório Anual da Rede Social de Justiça e Direitos Humanos (2007, p. 13) afirma que:

A consciência de que os "direitos humanos" precisam ser respeitados cresce em todos os continentes e constitui um dos pilares da construção de um "outro mundo possível". Para que essa construção chegue a termo, é indispensável definir "direito humano" como aquele direito inerente à pessoa em si, independentemente da sua nacionalidade, da sua classe social, da sua religião, da sua condição pessoal.

No tocante ao discurso dos direitos humanos das mulheres, é importante observar que "o Brasil é signatário de todos os acordos internacionais que asseguram de forma direta ou indireta os direitos humanos das mulheres bem como a eliminação de todas as formas de discriminação e violência baseadas no gênero" (FREIRE, 2006, p. 9).

Logo, a promoção e afirmação dos direitos humanos no cotidiano do contexto escolar são vistas como uma possibilidade de encurtar e minimizar as distâncias e desigualdades culturais, sociais, políticas e econômicas existentes em nossa sociedade, bem como oportunizar a apropriação de saberes sobre a noção de direitos que viabilizem e fortaleçam laços de convivência de nossos educandos, tendo presente o respeito à diversidade e à pluralidade com relação aos jeitos diferentes de ser e de conviver (BRASIL, 2009).

Nesse sentido, as Diretrizes Curriculares Nacionais da Educação Básica afirmam que: 
Educar para os direitos humanos, como parte do direito à educação, significa fomentar processos que contribuam para a construção da cidadania, do conhecimento dos direitos fundamentais, do respeito à pluralidade e à diversidade de nacionalidade, etnia, gênero, classe social, cultura, crença religiosa, orientação sexual e opção política, ou qualquer outra diferença, combatendo e eliminando toda forma de discriminação (BRASIL, 2013a, p. $165)$.

Com base nos Parâmetros Curriculares Nacionais, as crianças devem dominar os conhecimentos de que necessitam para crescerem como cidadãos plenamente reconhecidos e conscientes de seu papel em nossa sociedade, e isso só será alcançado se oferecermos a elas pleno acesso aos recursos culturais relevantes para a conquista de sua cidadania, como preocupações com o meio ambiente, com a saúde, com a sexualidade e com as questões éticas relativas à igualdade de direitos, à dignidade do ser humano e à solidariedade (PCN, 1997).

Assim, é necessário que a escola reconheça o seu papel importante na educação para combater as relações autoritárias, questionar a rigidez dos padrões de conduta estabelecidos para homens e mulheres e apontar para sua transformação, devendo desenvolver, também, uma ação educativa voltada para refletir em torno de discussões referentes à saúde e ao bemestar do ser humano e às questões de gênero.

A Base Nacional Comum Curricular (BNCC) reconhece que a Educação Básica deve visar à formação e ao desenvolvimento humano global em suas dimensões intelectual, física, afetiva, social, ética, moral e simbólica. Isso implica assumir uma visão plural, singular e integral da criança, do adolescente, do jovem e do adulto - considerando-os como sujeitos de aprendizagem - e promover uma educação voltada ao seu acolhimento, reconhecimento e desenvolvimento pleno, nas suas singularidades e diversidades. Além disso, a escola, como espaço de aprendizagem e de democracia inclusiva, deve se fortalecer na prática coercitiva de não discriminação, não preconceito e respeito às diferenças e diversidades (BRASIL, 2017).

Referência para a construção dos currículos de todas as escolas do país, a BNCC estabeleceu como pilares dez competências gerais que irão nortear o trabalho das escolas e dos professores em todos os anos e componentes curriculares, apontando para a necessidade de os alunos serem capazes de utilizar os saberes que adquirirem para dar conta do seu dia a dia, sempre respeitando princípios universais, como a ética, os direitos humanos, a justiça social e a sustentabilidade ambiental.

Cabe ressaltar que as escolas brasileiras continuam tendo a missão de assegurar a aprendizagem dos alunos nos componentes curriculares tradicionais, mas também devem ampliar a capacidade de lidar com pensamento crítico, sensibilidade cultural, diversidade, autoconhecimento, autocuidado, emoções, empatia, colaboração, autonomia, ética, 
diversidade, responsabilidade, consciência socioambiental e cidadania, entre outros aspectos importantes para a vida no século XXI.

É importante, então, considerar que a escola é um espaço privilegiado para permitir situações de vivências e de aprendizagens, tanto pelo currículo formal como com a participação de novos atores sociais, permitindo espaços que possibilitem pensar como os direitos humanos possam se tornar presentes na realidade de cada indivíduo, problematizando temas do nosso dia a dia, como a não violência doméstica e familiar contra mulheres e o não preconceito, que possam tornar a vida a ser vivida mais digna e menos injusta (BRASIL, 2009, p. 20).

Nesse contexto, a Educação Sexual se propõe a ser uma ferramenta útil de transformação social. De forma geral, a educação básica já tem como objetivos a eliminação de opressões e desigualdades. Conforme o Ministério da Educação, a educação tem "por finalidades desenvolver o educando, assegurar-lhe a formação indispensável para o exercício da cidadania e fornecer-lhe meios para progredir no trabalho e em estudos posteriores, contribuindo para a redução das desigualdades sociais" (MEC, 2015). Neste sentido, a Educação Sexual alia-se aos objetivos gerais da educação básica.

\section{Considerações finais}

A importância da educação no processo de ensino-aprendizagem e socialização, visando a consolidação do exercício de direitos e a construção da cidadania, é um meio fundamental para o desmonte das desigualdades sociais de gênero.

A Educação Sexual é uma via útil para educar o indivíduo a exercer sua sexualidade de forma autônoma, bem como para educar na construção de uma sociedade mais justa e igual que respeite as diferenças e reconheça o valor intrínseco de cada ser humano independente.

O processo educacional, por meio da educação sexual e da promoção da equidade de gênero, é importante veículo de mudança da sociedade, eis que visa a formação de indivíduos mais críticos e aumenta o poder de reflexão dos alunos e sobre a própria realidade; desperta a cidadania e o questionamento nos alunos; forma cidadãos conscientes, funcionando com um antídoto contra o preconceito, fazendo com que eles percebam o mundo de forma crítica e plural e sejam capazes de construir uma sociedade mais justa, ética, democrática, responsável, inclusiva, sustentável e solidária.

Tais ações educacionais no âmbito escolar promovem uma mudança cultural a partir da disseminação de direitos humanos, cidadania e valores éticos de irrestrito respeito à dignidade humana com a perspectiva de gênero e às diversidades, visando a orientação sexual, 
o enfrentamento da violência doméstica e familiar contra mulheres e a construção de uma cultura igualitária, democrática e não reprodutora de estereótipos de gênero.

\section{REFERÊNCIAS}

AMORIM, S. N. D. O combate à violência contra a mulher: a luta entre antigos valores e novos padrões de políticas públicas. Casoteca de Gestão Pública. Brasília, DF: ENAP, 2012. 8 p.

AVELAR, L. Mulheres na elite política brasileira. 2 ed. São Paulo: Konrad Adenauer, 2001. $188 \mathrm{p}$.

ASSOCIAÇÃO NOVA ESCOLA. BNCC na prática: aprenda tudo sobre as competências gerais. Associação Nova Escola. Fundação Lemann. Disponível em:

https://novaescola.org.br/bncc/conteudo/103/faca-o-download-do-livro-sobre-as-

competencias-gerais-em-pdf. Acesso em: 25 mar. 2019.

BRASIL. Constituição (1988). Constituição da República Federativa do Brasil. Brasília, DF: Senado, 1988.

BRASIL. Lei n. 9.394, de 20 de dezembro de 1996. Lei de Diretrizes e Bases da Educação Nacional. Diário Oficial da União: Seção 1, Brasília, DF, n. 248, p. 27833, 23 dez. 1996.

BRASIL. Ministério da Educação. Secretaria de Educação Fundamental. Parâmetros Curriculares Nacionais: introdução aos parâmetros curriculares nacionais. Secretaria de Educação Fundamental. Brasília: MEC/SEF, 1997. 126 p.

BRASIL. Ministério da Educação. Secretaria de Educação Fundamental. Parâmetros Curriculares Nacionais: terceiro e quarto ciclos - apresentação dos temas transversais. Brasília: MEC/ SEF, 1998.

BRASIL. Presidência da República. Secretaria Especial de Políticas para as Mulheres. Programa de prevenção, assistência e combate à violência contra a mulher - Plano Nacional: diálogos sobre violência doméstica e de gênero, construindo políticas públicas. Brasília: Presidência da República, 2003. 66 p.

BRASIL. Lei n. 11.340, de 7 de agosto de 2006. Lei Maria da Penha. Diário Oficial da União: Seção 1, Brasília, DF, n. 248, p. 1, 8 ago. 2006. PL 4559/2004

BRASIL. Presidência da República. Secretaria Especial de Políticas para as Mulheres. II Plano Nacional de Políticas para as Mulheres. Brasília: Secretaria Especial de Políticas para as Mulheres, 2008. 237 p.

BRASIL. Ministério da Educação. Secretaria de Educação Básica. Direitos humanos em educação. Série: cadernos pedagógicos. Programa Mais Educação. Brasília, 2009. 68 p.

BRASIL. Presidência da República. Secretaria de Políticas para Mulheres. $7^{\mathbf{0}}$ prêmio construindo a igualdade de gênero. Brasília: SPM/PR, 2012. 226 p.

RPGE- Revista on line de Política e Gestão Educacional, Araraquara, v. 24, n. esp. 3, p. 1727-1742, dez., 2020. e-ISSN:1519-9029 
BRASIL. Ministério da Educação. Secretaria de Educação Básica. Diretrizes Curriculares Nacionais para Educação Básica. Brasília: MEC/SEF, 2013a. 546 p.

BRASIL. Presidência da República. Secretaria Especial de Políticas para as Mulheres. Plano Nacional de Políticas para as Mulheres: 2013-2015. Brasília: Secretaria Especial de Políticas para as Mulheres, 2013b. 114 p.

BRASIL. Ministério da Educação. Base Nacional Comum Curricular. 2017. Disponível em:

http://basenacionalcomum.mec.gov.br/images/BNCC_EI_EF_110518_versaofinal_site.pdf. Acesso em: 5 abr. 2019.

BRASIL. Ministério da Educação. Principais Ações e Programas de responsabilidade do Ministério da Educação no PPA 2012-2015. Disponível em:

http://portal.mec.gov.br/secretaria-de-educacao-basica/programas-e-acoes. Acesso em: 06 abr. 2019.

CÉSAR, M. R. A. Gênero, sexualidade e educação: notas para uma “epistemologia”. Educar, Curitiba, n. 35, p. 37-51, 2009,

CHAUÍ, M. Repressão Sexual, essa nossa (des)conhecida. 12. ed. São Paulo: Brasiliense, 1991.

COELHO, S.; ZELIC, H. Passos da luta pelo fim da violência contra as mulheres. In:

Relatório anual da rede social de justiça e direitos humanos. 2018. p. 156-162.

CROCIARI, A.; PEREZ, M. C. A. O que estamos estudando sobre gênero na educação infantil: as lacunas na formação docente. Dossiê Sexualidade, gênero e educação sexual em debate. Rev. Ibero-Americana de Estudos em Educação, Araraquara, SP, Brasil, v .14, n. esp. 2, p. 1556-1568, jul. 2019. e-ISSN: 1982-5587. DOI:

https://doi.org/10.21723/riaee.v14iesp.2.12615

DATA FOLHA. Fórum Brasileiro de Segurança Pública (FBSP). Visível e invisível: a vitimização de mulheres no Brasil. 2. ed. Datafolha/FBSP, 2019.

DALLARI, D. Policiais, juízes e igualdades de direitos. In: LERNER, J. (Ed.). O

preconceito. São Paulo: Imprensa Oficial do Estado, 1996/1997.

FIGUEIRÓ, M. N. D. Educação sexual: retomando uma proposta um desafio. 3. ed. Londrina: EDUEL, 2010.

FOUCAULT, M. Vigiar e punir: nascimento da prisão. Petrópolis, RJ: Vozes, 1987.

FOUCAULT, M. História da sexualidade: o cuidado de si. Rio de Janeiro: Graal, 2005.

FREIRE, P. Pedagogia da esperança: um reencontro com a Pedagogia do oprimido. São Paulo: Paz e Terra, 2006. 
FUNDAÇÃO VICTOR CIVITA. Ética e cidadania. In: Ofício de professor: aprender mais para ensinar melhor. São Paulo: Abril, 2002.

GUERRA, I. C. Pesquisa qualitativa e análise de conteúdo: sentidos e formas de uso. Portugal: Principia, 2006.

HUMAN RIGHTS WATCH (HRW). Word Report 2019 (events of 2018). Brasil: eventos de 2018. 2019. Disponível em: https://www.hrw.org/pt/world/report/2019/countrychapters/325547. Acesso em: 20 jun. 2020.

LIBÂNEO, J. C.; SILVA, E. Finalidades educativas escolares e escola socialmente justa: a abordagem pedagógica da diversidade social e cultural. Rev. on line de Política e Gestão Educacional, Araraquara, v. 24, n. esp. 1, ago. 2020. e-ISSN: 1519-9029. DOI: https://doi.org/10.22633/rpge.v24iesp1.13783

LOURO, G. L. Gênero, sexualidade e educação: das afinidades políticas às tensões teóricometodológicas. Educação em revista, Belo Horizonte, n. 46, p. 201-2018, dez. 2007.

LOURO, G. L. Gênero, sexualidade e educação: uma perspectiva pós-estruturalista. Petrópolis, RJ: Vozes, 2012. 185 p.

LUCIFORA, C. A.; REINA, F. T.; MUZZETI, L. R.; SILVA, R. A. Marcas sociais de nossos tempos: gênero, sexualidade e educação em âmbito escolar. Dossiê Sexualidade, gênero e educação sexual em debate. Rev. Ibero-Americana de Estudos em Educação, Araraquara, v. 14, n. esp. 2, jul. 2019. e-ISSN: 1982-5587. DOI:

https://doi.org/10.21723/riaee.v14iesp.2.12607

LÜDKE, M.; ANDRE, M. E. D. A. A Pesquisa em educação: abordagens qualitativas. 2. ed. Rio de Janeiro: E.P.U., 2013.

MAIA, A. C. B. Sexualidade e educação sexual. Disponível em: https://acervodigital.unesp.br/bitstream/unesp/155340/3/unespnead_reei1_ee_d06_s03_texto02.pdf. Acesso em: 6 abr. 2019.

MAIA, A. C. B.; RIBEIRO, P. R. M. Educação sexual: princípios para ação. Doxa: Revista Paulista de Psicologia e Educação, Araraquara, v. 15, n. 1, p. 75-84, 2011. ISSN 1413-2060. Disponível em:

https://www.academia.edu/12736279/Educa\%C3\%A7\%C3\%A3o_Sexual_princ\%C3\%ADpio s_para_a\%C3\%A7\%C3\%A3o. Acesso em: 10 out. 2020.

MANZINI, E. J. A entrevista na pesquisa social. São Paulo: Didática, 1990/1991. v. 26/27.

NOGUEIRA, J. K.; FELIPE, D. A.; TERUYA, T. K. Conceitos de gênero, etnia e raça: reflexões sobre a diversidade cultural na educação escolar. Fazendo Gênero 8 - Corpo, Violência e Poder. Florianópolis, 2008.

NOGUEIRA, N. S. et al. Educação sexual no contexto escolar: as estratégias utilizadas em sala de aula pelos educadores. Holos, ano 32, v. 3, 2016. 
RABELO, A. O.; PEREIRA, G. R.; REIS, M. A. S. Formação docente em gênero e sexualidade: entrelaçando teorias, políticas e práticas. 1. ed. Petrópolis, RJ: De Petrus et Alii, 2013.

RAYA, L. C. Educação: caminho para a liberdade. Rio Claro: Franciscana, 1981. 198 p.

RELATÓRIO Anual da Rede Social de Justiça e Direitos Humanos. 2007. Disponível em: www.social.org.br. Acesso em: 7 abr. 2019.

SANTOS, C. M. Direitos humanos das mulheres e violência contra as mulheres: avanços e limites da Lei "Maria da Penha". In: Relatório Anual da Rede Social de Justiça e Direitos Humanos. 2007. p. 193-202. Disponível em: www.social.org.br. Acesso em: 7 abr. 2019.

SILVA, A. S. Direitos Humanos em lugares minoritários: um convite ao pensar sobre processos de exclusão na escola. In: Programa ética e cidadania: construindo valores na escola e sociedade. 2007. Disponível em:

portal.mec.gov.br/seb/arquivos/pdf/Etica/11_soares.pdf. Acesso em: 6 abr. 2019.

TAVARES, A. C. C.; NERY, I. S. Violência doméstica conjugal contra as mulheres: uma reflexão acerca da dimensão simbólica proposta por Pierre Bourdieu. In: ENCONTRO NACIONAL DA REDE FEMINISTA E NORTE E NORDESTE DE ESTUDOS E PESQUISA SOBRE A MULHER E RELAÇÕES DE GÊNERO, 17., 2012, João Pessoa. Anais [...]. João Pessoa, PB: UFPB, dez. 2012. Disponível em:

http://www.ufpb.br/evento/index.php/17redor/17redor/paper/view/125/60. Acesso em: 09 dez. 2019.

TEIXEIRA, F.; MARQUES, F. M. A educação em sexualidade e os media. Revista Elo, v. 19, 2012. Disponível em:

https://www.researchgate.net/publication/282851974_A_EDUCACAO_EM_SEXUALIDAD E_E_OS_MEDIA_-_Revista_Elo_n_19_2012. Acesso em: 4 abr. 2019.

VACCARI, V. L. Projeto cidadania e gênero: superando a violência contra a mulher. Gênero e Pesquisa, Uberlândia, ano 9, n. 17, p. 2-8, 2001.

WAS. World Association Sexology. Declaração dos Direitos Sexuais como Direitos Sexuais. Hong-Kong, 1999. 


\section{Como referenciar este artigo}

AZADINHO, M. P. M. A.; OLIVEIRA, A. L.; MILANI, D. R. C. A educação sexual e a promoção da equidade de gênero no enfrentamento da violência doméstica contra mulheres. Revista on line de Política e Gestão Educacional, Araraquara, v. 24, n. esp. 3, p. 1727 1742, nov., 2020. e-ISSN:1519-9029. DOI: https://doi.org/10.22633/rpge.v24iesp3.14280

Submetido em: 10/01/2020

Revisões requeridas: 20/07/2020

Aprovado em: $30 / 10 / 2020$

Publicado em: 30/11/2020 